\title{
A survey of awareness and knowledge of mother-to-child transmission of HIV in pregnant women attending Olabisi Onabanjo University Teaching Hospital, Sagamu, Nigeria*
}

\author{
Mustafa Adelaja Lamina \\ Department of Obstetrics and Gynaecology, Olabisi Onabanjo University Teaching Hospital, Sagamu, Nigeria \\ Email: ademustapha_2003@yahoo.co.uk
}

Received 6 January 2012; revised 22 February 2012; accepted 29 February 2012

\begin{abstract}
Objective: To determine the knowledge and awareness of Human Immunodeficiency Virus (HIV)/Acquired Immunodeficiency Syndrome (AIDS) and mother-to-child transmission (MTCT) among women attending the antenatal clinic. Methods and Subjects: This was primarily a descriptive cross-sectional study carried out at the antenatal clinic of Olabisi Onabanjo University Teaching Hospital (OOUTH), Sagamu, Nigeria from July $1^{\text {st }}, 2010$ to October $31^{\text {st }}$, 2010. Results: The age range of the respondents was 18 - 41 years, (mean $29 \pm 5$ years). One hundred and forty-nine $(92.5 \%)$ were married. All the respondents interviewed were aware of HIV/AIDS and $93(57.8 \%)$ had been aware of the disease for $\geq 5$ years. The main sources of information were television $93(57.8 \%)$, radio $77(47.8 \%)$, health workers $53(32.9 \%)$, friends, relatives and neighbors $41(25.5 \%)$ and posters 34 (21.1\%). Majority of the respondents identified sexual intercourse as a route of transmission of HIV. Sharing of sharp objects and blood transfusion were identified as routes of transmission by $99(61.5 \%)$ and $82(50.9 \%)$ respectively. One hundred and sixteen (72\%) of the respondents knew an apparently healthy person could be living with HIV. Majority of the respondents $125(77.6 \%)$ were aware that HIV can coexist with pregnancy and $120(74.5 \%)$ were aware of MTCT of HIV. Vaginal delivery and breastfeeding were identified as routes of HIV transmission by 44 $(27.3 \%)$ and $53(32.9 \%)$ of respondents respectively. Delivery by caesarean section was identified as a method of prevention of MTCT by $25(15.5 \%)$ respondents while as many as $48(29.8 \%)$ respondents did not know any method of prevention of MTCT of HIV. Conclusion: This study demonstrates a low level
\end{abstract}

"Declaration of conflict of interest: the author declares that there is no conflict of interest and that the study was self-sponsored. of awareness of methods of prevention of MTCT of HIV among pregnant women booking for antenatal care in our center. Thus, there is the need for adequate counseling about HIV/AIDS and specific aspects of prevention of mother-to-child transmission in our antenatal clinics.

Keywords: Awareness; Knowledge; Mother-to-Child; Transmission; HIV

\section{INTRODUCTION}

Nigeria accounts for about $10 \%$ of all HIV/AIDS cases in the world [1]. Women constitute $57 \%$ of adults infected with HIV in Nigeria, a prevalence which is higher than that of the global figure of $48 \%$. Sixty percent of new infections occur in the 15 - 25-year-old age group but the prevalence is highest among productive young people between the ages of $20-29$ years [2,3]. Heterosexual transmission accounts for $80 \%$ of all infections [3]. The pandemic is having a ruinous effect on the reproductive health of women in Nigeria [1,3].

The number of HIV-positive women has increased, with an attendant alarming increase in the number of HIV-positive children in recent years [1]. In 2007, around 370,000 children under 15 became infected with HIV, mainly through mother-to-child transmission. About $90 \%$ of these MTCT infections occurred in Africa where AIDS is beginning to reverse decades of steady progress in child survival. In high income countries of the world, MTCT has been virtually eliminated thanks to effective voluntary testing and counseling, access to antiretroviral therapy, safe delivery practices, and the widespread availability and safe use of breast-milk substitutes. If these interventions were used worldwide, they could save lives of thousands of children each year. Hence, there is an urgent need to combat this menace $[4,5]$.

Olabisi Onabanjo University Teaching Hospital, Sagamu is a tertiary health facility situated in Sagamu, a 
sub-urban local government headquarter of Sagamu local government area of Ogun State in Western Nigeria. The prevention of mother-to-child transmission services was initiated at the Olabisi Onabanjo University Teaching Hospital, Sagamu in September 2006. Following the designation of the center for its program on prevention of mother-to-child transmission, it became pertinent to determine the knowledge and awareness of HIV/AIDS and mother-to-child transmission among women attending the antenatal clinic. The information obtained shall influence the counseling and education of patients and the community on HIV/AIDS, which, we suspect, will in turn decrease mother-to-child transmission of HIV/AIDS.

\section{METHOD AND SUBJECTS}

\subsection{Sample Size}

This was primarily a descriptive study. The sample size was calculated from the expression: $N=Z^{2} \cdot(100-p) p / d$ [2]. $\mathrm{Z}$ is a standard normal deviate usually set at 1.96 . The confidence level was specified as $95 \%$ and the tolerable error margin (d) is 5\%. Several specifications for $\mathrm{p}$ were made based on the study objectives. The largest sample size, which satisfied all objectives, was used, and a sample of 126 respondents was needed $(p=91)$, which was the prevalence of awareness of coexistence of HIV and pregnancy among pregnant women in a similar study [6]. The sample size was adjusted to compensate for a non-response rate of $20 \%$. Thus, the final minimum sample size is 151 .

\subsection{Setting, Instrument and Data Collection}

The study was carried out at the antenatal clinic of Olabisi Onabanjo University Teaching Hospital, Sagamu from July $1^{\text {st }}, 2010$ to October $31^{\text {st }}$, 2010. Antenatal clinics are run for three days in a week, with average total attendance and new antenatal bookings of 45 and 10 per week respectively. The instrument used was a questionnaire designed to assess awareness of the women about HIV/AIDS, evaluate their knowledge of possible routes of transmission particularly mother-to-child transmission and measures to prevent vertical transmission from mother to child (Appendix). It included sociodemographic information such as age, marital status, level of education and parity. Questions were asked on whether they have heard of HIV/AIDS, identification of specific routes of transmission of HIV, whether a healthy person can be infected with HIV, the possibility of HIV coexisting with pregnancy and transmission to the infant, timing of transmission from mother to child and awareness of measures to prevent mother-to-child transmission. The questionnaire was then pretested for comprehensibility, appropriateness of language, sensitivity of questions and average duration of administration. The interviewers were registrars who were trained on interviewing techniques, eligibility of respondents, and a detailed explanation of each question and role-play. All patients who were newly booking for antenatal care in the hospital during the study period was listed at the booking visit. The nature of the study was explained to them and their consent was obtained. Only those willing to be interviewed were included in the study. Interview was done before they were counseled about HIV/AIDS and testing.

\subsection{Data Analysis}

The data was analysed using the SPSS package version 15.0. For the descriptive aspects of the analysis, frequency distributions were generated for all categorical variables. Means and standard deviation were determined for quantitative variables. The chi-squared test was applied for the comparison of proportions and for evaluating association of categorical variables. Statistical significance was said to be achieved where the $p$ value is $<0.05$.

\section{RESULTS}

Out of one hundred and sixty seven women that were booked for antenatal care during the study period, 161 agreed to be interviewed. The remaining six were not interested to participate in the study. The age range of the respondents was $18-41$ years, with a mean age of $29 \pm 5$ years. More than half of the respondents, 100 (62.1\%) has had at least one delivery while a majority, 111 $(68.9 \%)$ of the respondents were Christians. One hundred and forty-nine (92.5\%) were married and $76(47.2 \%)$ had at least secondary education (Table $\mathbf{1}$ ).

Table 2 shows the awareness and knowledge of HIV/ AIDS among the respondents. All the respondents interviewed were aware of HIV/AIDS and more than half, 93 $(57.8 \%)$ had been aware of the disease for $\geq 5$ years. The main sources of information were television 93 (57.8\%), radio $77(47.8 \%)$, health workers 53 (32.9\%), friends, relatives and neighbors $41(25.5 \%)$ and posters 34 $(21.1 \%)$. The religious homes, churches and mosques had the least number of respondents 33 (20.5\%). Two respondents identified school as the source of information. Majority of the respondents, $127(78.9 \%)$ identified sexual intercourse as a route of transmission of HIV. Sharing of sharp objects and blood transfusion were identified as routes of transmission by 99 (61.5\%) and 82 $(50.9 \%)$ respectively. Interestingly, a respondent believed prolonged kiss with an infected person as a route of transmission of HIV. A significantly higher proportion of the respondents $116(72 \%)$ knew an apparently healthy 
Table 1. Sociodemographic characteristics of the study population.

\begin{tabular}{|c|c|c|}
\hline Age (years) & Number & Percentage \\
\hline $15-19$ & 4 & 2.5 \\
\hline $20-24$ & 29 & 18.0 \\
\hline $25-29$ & 54 & 33.5 \\
\hline $30-34$ & 48 & 29.8 \\
\hline $35-39$ & 22 & 13.7 \\
\hline$\geq 40$ & 4 & 2.5 \\
\hline \multicolumn{3}{|l|}{ Parity } \\
\hline 0 & 61 & 37.9 \\
\hline 1 & 45 & 28.0 \\
\hline 2 & 30 & 18.6 \\
\hline 3 & 18 & 11.2 \\
\hline 4 & 7 & 4.3 \\
\hline \multicolumn{3}{|l|}{ Marital status } \\
\hline Single & 10 & 6.2 \\
\hline Married & 149 & 92.5 \\
\hline Separated & 1 & 0.6 \\
\hline Divorced & 1 & 0.6 \\
\hline Widowed & - & - \\
\hline \multicolumn{3}{|l|}{ Educational level } \\
\hline None & 3 & 1.9 \\
\hline Primary & 16 & 9.9 \\
\hline Secondary & 57 & 35.4 \\
\hline Tertiary & 85 & 52.8 \\
\hline \multicolumn{3}{|l|}{ Occupation } \\
\hline Trading & 50 & 31.1 \\
\hline Teaching & 30 & 18.6 \\
\hline Other civil servants & 18 & 11.2 \\
\hline Professional & 13 & 8.1 \\
\hline Students & 20 & 12.4 \\
\hline Artisan & 15 & 9.3 \\
\hline Corper & 3 & 1.9 \\
\hline Housewife & 10 & 6.2 \\
\hline Unemployed & 2 & 1.2 \\
\hline Total & 161 & 100.0 \\
\hline Gestational age & Number & Percentage \\
\hline$\leq 12$ & 11 & 6.8 \\
\hline $13-17$ & 36 & 22.4 \\
\hline $18-22$ & 35 & 21.7 \\
\hline $23-27$ & 36 & 22.4 \\
\hline $28-32$ & 29 & 18.0 \\
\hline $33-37$ & 12 & 7.5 \\
\hline$\geq 38$ & 2 & 1.2 \\
\hline Total & 161 & 100.0 \\
\hline
\end{tabular}

Table 2. Awareness and knowledge of HIV/AIDS.

\begin{tabular}{|c|c|c|}
\hline Awareness of HIV/AIDS & Number & Percentage \\
\hline Yes & 161 & 100 \\
\hline No & 0 & 0 \\
\hline \multicolumn{3}{|c|}{ Duration of awareness } \\
\hline$<5$ years & 68 & 42.2 \\
\hline$\geq 5$ years & 93 & 57.8 \\
\hline Total & 161 & 100.0 \\
\hline \multicolumn{3}{|c|}{ Sources of information } \\
\hline Television & 93 & 57.8 \\
\hline Radio & 77 & 47.8 \\
\hline Newspapers & 36 & 22.4 \\
\hline Posters & 34 & 21.1 \\
\hline Health workers & 53 & 32.9 \\
\hline Friends/relatives/neighbors & 41 & 25.5 \\
\hline Religious homes & 33 & 20.5 \\
\hline Others & 8 & 5.0 \\
\hline \multicolumn{3}{|c|}{ Route of transmission } \\
\hline Sexual intercourse & 127 & 78.9 \\
\hline Sharing sharps & 99 & 61.5 \\
\hline Blood transfusion & 82 & 50.9 \\
\hline Mother-to-child & 65 & 40.4 \\
\hline Others & 7 & 4.3 \\
\hline \multicolumn{3}{|c|}{ Infected person can be healthy } \\
\hline Yes & 116 & 72.0 \\
\hline No & 26 & 16.1 \\
\hline Don't know & 19 & 11.8 \\
\hline Total & 161 & 100.0 \\
\hline
\end{tabular}

person could be living with HIV.

Table 3 shows that majority of the respondents 125 $(77.6 \%)$ were aware that HIV can coexist with pregnancy and $120(74.5 \%)$ were aware of mother-to-child transmission of HIV. A small but notable proportion of the respondents, $32(19.9 \%)$ were not aware that HIV could be transmitted from mother to child. Transmission during pregnancy (transplacental route) was known by 79 (49.1\%) of the respondents as a mode of mother-to-child transmission of HIV. However, a significantly lower proportion of the respondents identified vaginal delivery and breastfeeding as routes of HIV transmission [44 $(27.3 \%)$ and $53(32.9 \%)$ respectively]. Caesarean section was identified as a route of HIV transmission by 12 (7.5\%) respondents, a proportion that was statistically significantly lower than $44(27.3 \%)$ respondents that believed vaginal delivery as a route of mother-to-child 
Table 3. Knowledge about HIV/AIDS and pregnancy.

\begin{tabular}{|c|c|c|}
\hline HIV coexistence with pregnancy & Number & Percentage \\
\hline Yes & 125 & 77.6 \\
\hline No & 18 & 11.2 \\
\hline Don’t know & 18 & 11.2 \\
\hline Total & 161 & 100.0 \\
\hline \multicolumn{3}{|c|}{ Mother-to-child transmission } \\
\hline Yes & 120 & 74.5 \\
\hline No & 9 & 5.6 \\
\hline Don’t know & 32 & 19.9 \\
\hline Total & 161 & 100.0 \\
\hline \multicolumn{3}{|c|}{ Routes of transmission } \\
\hline Placental & 79 & 49.1 \\
\hline Vaginal delivery & 44 & 27.3 \\
\hline Delivery by caesarean section & 12 & 7.5 \\
\hline Breastfeeding & 53 & 32.9 \\
\hline Others & 3 & 1.9 \\
\hline Don’t know & 36 & 22.4 \\
\hline \multicolumn{3}{|c|}{ Methods of preventing MTCT } \\
\hline ART during pregnancy & 66 & 41.0 \\
\hline ART in labor & 30 & 18.6 \\
\hline Delivery by c-section & 25 & 15.5 \\
\hline ART to newborn & 30 & 18.6 \\
\hline Avoid breastfeeding & 47 & 29.2 \\
\hline Others & 7 & 4.3 \\
\hline Don’t know & 48 & 29.8 \\
\hline
\end{tabular}

ART: antiretroviral therapy.

transmission $(\mathrm{p}<0.05)$. Thirty-six $(22.4 \%)$ respondents claimed that they did not know any mode of transmission of HIV. Also, the use of antiretroviral drugs in pregnancy, antiretroviral drugs given to newborn and avoidance of breastfeeding were identified as methods of reducing mother-to-child transmission of HIV by only $66(41 \%)$, $30(18.6 \%)$ and $47(29.2 \%)$ of respondents, respectively. Delivery by caesarean section was identified as a method of prevention of mother-to-child transmission by 25 $(15.5 \%)$ respondents. As many as $48(29.8 \%)$ respondents did not know any method of prevention of motherto-child transmission of HIV.

Table 4 shows the knowledge of mother-to-child transmission of HIV transmission among women with no or primary education as compared with women who had at least secondary education. While $14(73.7 \%)$ of respondents with no or primary education were aware of mother-to-child transmission of HIV, ninety-five (66.9\%)
Table 4. Level of education and knowledge of mother-to-child transmission of HIV.

\begin{tabular}{ccc}
\hline \multirow{2}{*}{ Knowledge of MTCT } & \multicolumn{2}{c}{ Level of education } \\
\cline { 2 - 3 } & None/Primary (\%) & Secondary \& bove (\%) \\
\hline Yes & $14(73.7)$ & $95(66.9)$ \\
No & $5(26.3)$ & $47(33.1)$ \\
Total & $\mathbf{1 9 ( 1 0 0 )}$ & $\mathbf{1 4 2}(\mathbf{1 0 0})$ \\
\hline
\end{tabular}

$\mathrm{x}^{2}=0.35, \mathrm{p}$ value $=0.5526 ;$ odds ratio $=1.39 ;$ confidence interval $=0.44$ 5.20. HIV: Human Immunodeficiency Virus; MTCT: Mother-To-Child Transmission.

of women with at least secondary education were aware of mother-to-child transmission of HIV. The observed difference was not statistically significant $(\mathrm{p}$ value $=$ 0.5526 , odds ratio $(\mathrm{OR})=1.39$, confidence interval $=$ $0.44-5.20)$.

\section{DISCUSSION}

All the women in this study were aware of HIV/AIDS. This is uniform with the findings of the studies carried out by Abiodun et al. from Nigeria [6] and Luo and $\mathrm{He}$ from China [7]. In addition, majority of them demonstrated knowledge of mode of transmission and the course of the disease. This implies a high level of awareness among pregnant women attending the antenatal clinic in our hospital despite its location in a semi-urban community. More than half of them have been aware of the disease for 5 or more years. Similar high levels of awareness have been reported in other parts of the State and Nigeria [6-11]. Although about a tenth of the respondents had no or primary education, yet they are well aware of HIV/AIDS like their counterparts who had secondary or more education. This is quite impressive and may be as a result of recent national efforts to raise awareness through media campaign. Television, radio and health workers were the main media of information on HIV/AIDS among the pregnant women in the study. This is similar to the findings of Abiodun et al. at Ido-Ekiti in Ekiti State, Nigeria [6]. Median campaigns have been quite successful at increasing knowledge about HIV/AIDS in Nigeria and have been the first source of knowledge about HIV/ AIDS in the country [6,8-10].

Sexual intercourse was identified by $79 \%$ of respondents as a route transmission of HIV/AIDS and has the highest frequency among the routes of transmission. This is in line with a worldwide trend in which sexual intercourse is the route of transmission mostly known to pregnant women $[1,8]$. However, it is amazing that about $21 \%$ of the respondents were not aware that sexual intercourse is a route of transmission of HIV/AIDS infection. This portrays a great danger to these pregnant women and their community. Lack of accurate information about 
sexual health has permitted perpetuation of some myths and misconceptions, especially associating sexual immorality and HIV infection. This contributes to stigmatization and discrimination against people living with HIV/AIDS and increases transmission rates as well, not only in sub-Saharan Africa but also in developed parts of the world [1]. Many religious bodies perceive immoral behavior as the major cause of the HIV/AIDS epidemic and decline involvement in preventive and intervention programs [11]. In our study, religious bodies contributed least to HIV/AIDS awareness among the respondents. This was similar to findings by other authors [6,8-10]. Hence, there is a need for targeting religious leaders in the HIV/AIDS education and capacity-building campaigns for increased collaboration with HIV/AIDS prevention programs. Sharing of needles, razors and sharp objects, and blood transfusion were identified by $61.5 \%$ and $50.9 \%$ of respondents respectively, in this study as routes of transmission. This observation is similar to findings in other Nigerian studies [6,8-10]. It is also of interest that only $40.4 \%$ of the pregnant women in this study identified mother-to-child transmission as a means of transmission of HIV/AIDS infection. This is an indication that more work needs to be done on preventive educative programs for our pregnant women.

About $78 \%$ of the respondents were aware that HIV infection could coexist with pregnancy. A similar proportion $(75 \%)$ was aware of mother-to-child transmission of HIV. This study also showed that literate and illiterate respondents were equal in their awareness of mother-tochild transmission of HIV. Furthermore, specific knowledge of route or mode of mother-to-child transmission and the measures available to prevent it was low. Similarly low levels of knowledge have been reported in other parts of the country $[4,5,12,13]$ and also in Uganda [14], Tanzania [15] and China [7]. Forty-nine percent, $33 \%$ and $27.3 \%$ of respondents identified transplacental route, breastfeeding and vaginal delivery respectively as modes of transmission of HIV. It is quite impressive that a significant proportion of the respondents have the knowledge of transmission of HIV during pregnancy, breastfeeding and vaginal delivery. A lesser proportion (7.5\%) of the women believed HIV could be transmitted through caesarean section. This is unlike a similar study carried out at Ido-Ekiti, Nigeria where a significant proportion $(42.7 \%)$ of the respondents believed HIV could be transmitted through caesarean section [6]. This may be an indication that there may be a change of attitude to aversion to caesarean section for any indication usually shown by women in our environment where inability to deliver is often regarded by many communities in our region as reproductive failure [16].

More than a quarter $(29.8 \%)$ of the women in this study did not know of any method of preventing mother- to-child transmission of HIV. Avoiding breastfeeding was identified by $29.8 \%$ of the respondents, while only $15.5 \%$ of respondents mentioned caesarean section as a method of preventing mother-to-child transmission of HIV. However, while women may be (or may become) knowledgeable about the risk of transmitting HIV through the breast milk, avoiding breastfeeding in a region like ours may sometimes not be practicable because a substitute may not be acceptable, feasible, affordable, safe and sustainable for cultural, social and economic reasons [17]. Thus, there is a need for governmental and nongovernmental policies that will ensure a sustainable and effective breast milk substitute supply and utilization by infants of HIV-positive women, just as antiretroviral drugs are currently being made available for these women.

This study provides baseline information about knowledge of mother-to-child transmission of HIV and its prevention among women targeted for intervention in a high-risk zone in Africa. The women were interviewed before they were provided with information about HIV/ AIDS and mother-to-child transmission. Thus, the level of their knowledge closely reflects that of the larger community. Thus, policy changes that may result from the findings of this study will equally be relevant at the community level. However, the women were mostly married. In our own environment, the opinion of the male partners strongly influences the uptake of health policies and programs by women. Thus a more robust baseline assessment of knowledge is for the purpose of reducing mother-to-child transmission of HIV also requires the participation of men.

In summary, this study demonstrates a low level of awareness of methods of prevention of mother-to-child transmission of HIV among pregnant women booking for antenatal care in our center. Thus, there is the need for adequate counseling about HIV/AIDS and specific aspects of prevention of mother-to-child transmission in our antenatal clinics. Periodic assessment of the level of knowledge and impact of interventions are also required for re-evaluation of the counseling program. Focus should be on information on the risk of transmission, specific routes of mother-to-child transmission and various interventions available to prevent mother-to-child transmission. A public media campaign should also dwell more on the aspect of prevention of mother-to-child transmission for community education. Also, there is the need for increased collaboration with an HIV/AIDS prevention program by our religious organizations. Preliminary evaluation of knowledge, perceptions and attitude of religious leaders to HIV/AIDS education is needed. The level of current involvement of religious organizations in an HIV/AIDS prevention program also needs to be determined for an effective process of capacity-building and system strengthening. Finally, a more encompassing 
evaluation of knowledge and attitudes of the community about HIV/AIDS and mother-to-child transmission, including the male partners, will provide added information for establishing a community intervention program.

\section{ACKNOWLEDGEMENTS}

I wish to express my profound gratitude to the registrars and midwives of the antenatal clinic who assisted in data collection.

\section{REFERENCES}

[1] Joint United Nations Programme on HIV/AIDS (UNAIDS) (2006) Report on the global AIDS epidemic. www.unaids.org/en/HIV_data/2006GlobalReport/default. asp

[2] Federal Ministry of Health of Nigeria (FMOH)/National HIV/AIDS and STI Control Programme (HAST) (2006) The 2005 national HIV seroprevalence sentinel survey. Abuja: FMOH/HAST.

[3] US Aids for International Development (USAID) (2003) Nigeria country profile (HIV/AIDS). www.gov/location/sub-Saharan africa/countries/Nigeria

[4] UNAIDS/WHO (2005) AIDS epidemic update.

[5] UNAIDS/WHO (2005) Questions \& answers II-Basic facts about the HIV/AIDS epidemic and its impact.

[6] Abiodun, M.O., Ijaiya, M.A. and Aboyeji, P.A. (2007) Awareness and knowledge of mother-to-child transmission of HIV among pregnant women. Journal of National Medical Association, 99, 758-763.

[7] Luo, Y. and He, G.P. (2008) Pregnant women's awareness and knowledge of mother-to-child transmission of HIV in South Central China. Acta Obstetrica et Gynecologica Scandinavica, 87, 831-836. doi:10.1080/00016340802226342

[8] Aboyeji, A.P., Fawole, A.A. and Ijaiya, M.A. (2001) Knowledge and attitude to antenatal screening for HIV/ AIDS by pregnant women in Ilorin Nigeria. Nigeria Quar- terly Journal of Hospital Medicine, 10, 181-184.

[9] Igwegbe, A.O. and Llika, A.L. (2005) Knowledge and perceptions of HIV/AIDS and mother to child transmission among antenatal mothers at Nnamdi Azikwe University Teaching Hospital, Nnewi, Nigrria. International Journal of Clinical Practice, 8, 97-101.

[10] Adeneye, A.K., Mafe, M.A., Adeneye, A.A., et al. (2006) Knowledge and perception of HIV/AIDS among pregnant women attending antenatal clinics in Ogun State, Nigeria. African Journal of AIDS Research, 5, 273-279. doi: $10.2989 / 16085900609490389$

[11] Delius, P. and Glaser, C. (2005) Sex disease and stigma in South Africa: Historical perspective. African Journal of AIDS Research, 4, 29-36. doi:10.2989/16085900509490339

[12] Sotiloye, D., Fawole, A.O. and Hunyibo, K.I. (2001) Attitude of Abeokuta pregnant women to routine human immunodeficiency virus screening. Nigerian Journal of Medicine, 10, 173-176.

[13] Ezegwu, H.U., Ikeme, A.C. and Onwasigwe, C.N. (2005) Attitude of antenatal patients in Enugu towards HIV screening. Tropical Journal of Obstetrics Gynaecology, 22, 156-158.

[14] Yerda, M., Nedi, T. and Enquosolassia, F. (2002) Assessment of awareness of HIV/AIDS among selected target groups in and around Addis Ababa, Ethiopia. African Journal of Reproductive Health, 6, 30-37. doi: $10.2307 / 3583128$

[15] Harms, G., Mayer, A. and Karcher, H. (2003) Prevention of mother-to-child transmission of HIV in Kenya, Tanzania and Uganda. Report of Government of Tanzania PMTCT Project, International Coordination Office, Berlin, 1-26.

[16] Ezechi, O.C., Fasuba, O.B., Kalu, B.E.K., et al. (2004) Caesarean delivery: Why the aversion? Tropical Journal of Obstetrics and Gynecology, 21, 164-167.

[17] Federal Ministry of Health of Nigeria (FMOH) (2005) National guidelines on prevention of mother-to-child transmission of HIV in Nigeria, Abuja. 


\section{QUESTIONAIRE}

A survey of awareness and knowledge of mother to child transmission (MTCT) of HIV among pregnant women.

1) Age ......

2) Marital Status
a) Single
b) Married
c) Separated
d) Divorced
e) Widowed

3) Level of Education
a) None
b) Primary
c) Secondary
d) Tertiary

4) Occupation .......

5) Religion ......

6) Parity ......

7) Gestational age ......

8) Have you heard of HIV/AIDS? ......

9) How long have you been aware of HIV/AIDS?

10) What is the source of your information about HIV/ AIDS?
a) Friends, relatives, neighbors
b) Religious homes
c) Health workers
d) Radio
e) Television
f) Newspapers
g) Posters
h) Others (state)

11) How is HIV transmitted from one person to another?

a) Through sexual intercourse with infected partner

b) Through sharing sharp object with infected person

c) Through transfusion with infected blood

d) Through mother to child transmission

e) Others (state) .......

f) Don't know

12) Can an apparently healthy individual be infected with HIV?
a) Yes
b) No
c) Don't know

13) Can pregnant women be infected with HIV?

a) Yes

b) No

c) Don't know

14) Can an infected mother transmit the infection to her child?
a) Yes
b) No
c) Don't know

15) How can an infected mother transmit the infection to her child?
a) During pregnancy
b) Through vaginal delivery
c) Through caesarean section
d) Through breastfeeding
e) Others (state) ......
f) Don't know

16) How can mother to child transmission of infection be prevented?

a) Antiretroviral therapy during pregnancy

b) Delivery by caesarean section

c) Giving antiretroviral drugs to the newborn

d) Avoid breastfeeding

e) Others (state) .......

f) Don't know

\section{SURVEY OF AWARENESS AND \\ KNOWLEDGE OF MOTHER TO \\ CHILD TRANSMISSION OF HIV IN PREGNANT WOMEN ATTENDING OLABISI ONABANJO UNIVERSITY TEACHING HOSPITAL, SAGAMU}

\section{Inforemed Consent Form}

I am ......, of the Department of Obstetrics and Gynaecology, Olabisi Onabanjo University Teaching Hospital, Sagamu. I am investigating the awareness and knowledge of mother to child transmission of HIV in pregnant women attending the antenatal clinic of Olabisi Onabanjo University Teaching Hospital, Sagamu. You are being requested to kindly respond to questions on this subject.

If you agree to participate in this study, you will be asked questions relating to your awareness and knowledge of mother to child transmission of HIV in pregnant women. By participating in this study, you will contribute to our understanding of the level of awareness and knowledge of our pregnant women so that we can improve on our present strategy for prevention of mother to child transmission of HIV.

Any information you provide will be kept confidential and will not be used against you. Your name will not appear on the questionnaire. Your responses will not cause you any harm, neither will it prevent you from receiving the best of care from the hospital. You are free to choose whether you wish to participate. You are also free to discontinue responding to the questions at any time.

We hope you will participate and thank you for doing so.

Do you have any questions about the study? 


\section{CONSENT}

The study has been well explained to me and I understand fully the content of the research. I am willing to participate.

Signature of Participant/Date

Signature of Interviewer/Date 